\title{
Elevated Adenosine Deaminase Activity and Hereditary Hemolytic Anemia Evidence for Abnormal Translational Control of Protein Synthesis
}

\author{
Elaine G. Chottiner, Harry J. Cloft, Anthony P. Tartaglia, * and Beverly S. Mitchell \\ Division of Hematology-Oncology, Department of Internal Medicine, University of Michigan, Ann Arbor, Michigan 48109, \\ and *Division of Hematology, Department of Medicine, Albany Medical Center Hospital, Albany, New York 12208
}

\begin{abstract}
We have investigated the molecular basis of the marked elevation in erythrocyte adenosine deaminase (ADA) activity in a kindred with hereditary hemolytic anemia. Red cell ADA-specific activity was verified to be 70 - to 100 -fold normal levels. Western blots demonstrated a corresponding increase in erythrocyte ADAspecific immunoreactive protein. Analysis of genomic DNA revealed no evidence for amplification or major structural changes in the ADA gene. ADA-specific messenger RNA (mRNA) from proband reticulocytes was comparable in size and amount to mRNA from control reticulocytes. Translation of proband poly $A^{+}$reticulocyte mRNA in a rabbit reticulocyte lysate system and immunoprecipitation of ${ }^{35} \mathrm{~S}$-labeled protein products with antiADA antibody yielded $a$ band of $\sim 42,000$ apparent mol wt that was absent in translation products from control reticulocyte mRNAs. These data suggest that the increased ADA activity in red cells in this disorder results from the increased translation of an aberrant ADA mRNA.
\end{abstract}

\section{Introduction}

In 1970 Paglia et al. first described a kindred with a mild chronic hemolytic anemia and decreased adenine nucleotide pools (1). The specific defect in the red blood cells $(\mathrm{RBC})^{1}$ was later shown to be a 45- to 70-fold elevation of erythrocyte adenosine deaminase (ADA) activity over normal values in association with a 50-75\% depletion of ATP (2). The abnormality appeared to be tissue-specific in that ADA activity in leukocytes and skin fibroblasts was normal. The defect was inherited as an autosomal dominant trait, affecting 12 of 24 family members at risk. Extensive studies of ADA partially purified from proband RBC revealed normal kinetic and physicochemical properties, suggesting that erythrocytes contain an increased amount of structurally normal ADA protein $(3,4)$. Two additional kindreds

Address reprint requests to Dr. Beverly Mitchell, 5510 MSRB I, 1150 West Medical Center Drive, University of Michigan, Ann Arbor, MI 48109. 1986.

Received for publication 17 June 1986 and in revised form 9 October

1. Abbreviations used in this paper: ADA, adenosine deaminase; RBC, red blood cell.

J. Clin. Invest.

(c) The American Society for Clinical Investigation, Inc.

$0021-9738 / 87 / 03 / 1001 / 05 \$ \$ 1.00$

Volume 79, March 1987, 1001-1005 with similar clinical and biochemical findings have since been described $(5,6)$.

ADA is a purine catabolic enzyme that catalyzes the irreversible deamination of adenosine to inosine and 2'-deoxyadenosine to 2'-deoxyinosine. Deficiency of ADA has been causally associated with severe combined immunodeficiency disease, an autosomal recessive disorder characterized by B and T lymphocyte depletion (7). The pathophysiology of this syndrome appears to be related to substrate accumulation and the selective metabolism of 2'-deoxyadenosine to its corresponding 2'-deoxynucleotides in lymphoid cells (8). In the case of ADA overactivity, on the other hand, the increased catabolism of substrate results in an overall decrease in adenine ribonucleotide pools in erythrocytes and premature red cell destruction.

The molecular basis of erythrocyte ADA overactivity in this kindred has not yet been elucidated. We have asked whether the amount of erythrocyte ADA immunoreactive protein is indeed increased in this kindred and have investigated the molecular genetic basis of this defect.

\section{Methods}

Materials. Rabbit anti-human erythrocyte ADA antibody and ADA complementary DNA (cDNA) probes were kindly provided by Dr. Peter Daddona, University of Michigan, Ann Arbor, MI $(9,10)$. Highly purified human ADA was very kindly provided by Dr. Dan Wiginton and Dr. John Hutton, Children's Hospital Research Foundation, Cincinnati, $\mathrm{OH}$. ${ }^{35} \mathrm{~S}-\mathrm{Methionine,}{ }^{32} \mathrm{P}-\mathrm{dCTP},{ }^{14} \mathrm{C}$-labeled protein molecular weight standards, and $\mathrm{En}^{3} \mathrm{Hance}$ were obtained from New England Nuclear (Boston, MA). Restriction endonucleases and nick translation materials were obtained from Bethesda Research Laboratories (Bethesda, MD) and New England Biolabs (Beverly, MA). Except as noted in the text, all other reagents were purchased from Sigma Chemical Co. (St. Louis, MO).

Cell preparation. Blood from the proband, a second affected family member, normal subjects, and patients with hemolytic anemias (reticulocyte counts $>5 \%$ ) was collected in heparin- or EDTA-treated tubes. For protein and RNA experiments, mononuclear cells and plasma were removed from whole blood by centrifugation on a Ficoll-Hypaque gradient. Methylene blue and Wright-stained smears were examined microscopically to ensure that reticulocytes were preserved and leukocyte contamination accounted for $<5 \%$ of RNA-containing cells. Sources of $\mathrm{B}$ and $\mathrm{T}$ lymphoblast cell lines have been previously described (11).

Western blot analyses. Cultured lymphoblast and RBC extracts were prepared by freeze-thawing washed cell pellets three times in low salt buffer, containing $10 \mathrm{mM}$ Tris and $154 \mathrm{mM} \mathrm{NaCl}$ (pH 7.4), and then centrifuging for $30 \mathrm{~min}$ at $20,000 \mathrm{~g}$. The extracts were electrophoresed in a $10 \%$ SDS-polyacrylamide gel according to Laemmli (12) and transferred to nitrocellulose paper by the methods of Towbin et al. (13). Blots were rinsed in $50 \mathrm{mM}$ Tris, $150 \mathrm{mM} \mathrm{NaCl}(\mathrm{pH} \mathrm{8.0)}$ and incubated overnight at $4^{\circ} \mathrm{C}$ in blotto solution consisting of $10 \mathrm{mM}$ Tris, $140 \mathrm{mM}$ $\mathrm{NaCl}, 5 \%$ nonfat dry milk (Carnation Co., Los Angeles, $\mathrm{CA}$ ) (pH 7.4). 
Blots were then incubated for $2 \mathrm{~h}$ at $25^{\circ} \mathrm{C}$ in blotto solution containing $2 \mu \mathrm{l}$ rabbit anti-ADA antiserum, followed by a $2-\mathrm{h}$ incubation at $25^{\circ} \mathrm{C}$ in blotto solution containing $2 \mu \mathrm{l}$ goat anti-rabbit IgG antibody conjugated with horseradish peroxidase enzyme (Cooper Biomedical, Inc., Malvern, PA). Blots were stained in $8 \mathrm{mM}$ Tris, $20 \%$ methanol, $0.6 \mathrm{mg} /$ $\mathrm{ml}$ chloronaphthol, and $0.0015 \% \mathrm{H}_{2} \mathrm{O}_{2}(\mathrm{pH} 7.5)$.

Enzyme analysis. Cell extracts were assayed for ADA activity as previously described (14).

DNA extraction and Southern blot analysis. DNA was extracted from proband and normal human whole blood by the method of Bell et al. (15). Southern blot analysis was performed according to Maniatis (16). Blots were hybridized with a 1.5 -kb full-length ADA cDNA probe nick translated with ${ }^{32} \mathrm{P}-\mathrm{dCTP}$ to a specific activity of $\sim 10^{8} \mathrm{cpm} / \mu \mathrm{g}$.

$R N A$ extraction and Northern blot analysis. Total RNA was extracted from reticulocyte-rich, leukocyte-depleted blood prepared as described above. Frozen RBC pellets were thawed in 4 vol of cold 5-mM magnesium chloride, stirred for $5 \mathrm{~min}$ with 0.1 vol triisopropylnaphthalenesulfonic acid sodium salt (Eastman Kodak Co., Rochester, NY), and extracted with phenolchloroform. The aqueous phase was adjusted to $0.3 \mathrm{M}$ sodium chloride, reextracted with phenolchloroform, and precipitated overnight with 0.1 vol $3.0 \mathrm{M}$ sodium acetate (pH 5.2) and 2 vol $100 \%$ ethanol. The precipitate was washed in $70 \%$ ethanol, reprecipitated, and suspended in water at a concentration of $1-3 \mathrm{mg} / \mathrm{ml}$. Poly $A^{+} \mathrm{mRNA}$ was purified by oligo-(dT) cellulose chromatography as described by Aviv and Leder (17) with modifications to eliminate sodium and SDS from buffers.

A proband lymphoblastoid cell line was established by Epstein-Barr virus-mediated transformation of peripheral blood B lymphocytes by Dr. Peter Daddona (18). RNA was extracted from the proband and two normal B lymphoblast cell lines as well as from the MOLT-4 T lymphoblast cell line by centrifugation in a guanidium-cesium chloride gradient (16).

Northern blot analyses were performed using formaldehyde denaturing gels (16).

In vitro translation and immunoprecipitation. In vitro translation was performed in a rabbit reticulocyte lysate system (Amersham Corp., Arlington Heights, IL). Reactions were carried out in multiple aliquots containing $40 \mu \mathrm{l}$ of reticulocyte lysate, $113 \mu \mathrm{Ci}^{35} \mathrm{~S}$-methionine $(1.1 \mathrm{mCi} /$ mmol), and 300-500 ng poly $\mathrm{A}^{+}$messenger RNA (mRNA). Mixtures were incubated for $1 \mathrm{~h}$ at $30^{\circ} \mathrm{C}$. Reaction volumes were pooled and TCA-precipitable radioactivity determined on $5-\mu l$ aliquots.

Immunoprecipitation of ADA was carried out according to the method of Kessler (19). Pooled translation mixtures were diluted 1:2 in a buffer containing $25 \mathrm{mM}$ Tris, $50 \mathrm{mM} \mathrm{NaCl}, 0.5 \%$ deoxycholate, and $1 \% \mathrm{NP}-40$ (pH 7.4) (Buffer A) and the proband sample was divided into two equal aliquots. Lysates were incubated for $1 \mathrm{~h}$ with $2 \mu \mathrm{l}$ rabbit preimmune serum at $4^{\circ} \mathrm{C}$. Pansorbin $(100 \mu l$ of a $10 \%$ solution) (Behring Diagnostics, La Jolla, CA) was added and the suspension was incubated for $30 \mathrm{~min}$ at $4^{\circ} \mathrm{C}$ followed by centrifugation for $2 \mathrm{~min}$ at $5,000 \mathrm{~g}$. Purified human ADA $(11 \mu \mathrm{g})$ was added to one of the duplicate proband samples and all supernatants were then incubated for $1 \mathrm{~h}$ with $2 \mu \mathrm{l}$ rabbit antiADA antiserum. The Pansorbin precipitation was repeated, all Staphylococcal pellets were washed 3 times with Buffer $A$, and radiolabeled proteins were liberated by boiling for $4 \mathrm{~min}$ in a reducing buffer containing $63 \mathrm{mM}$ Tris, $2 \%$ SDS, $10 \%$ glycerol, and $5 \%$ 2-mercaptoethanol $(\mathrm{pH}$ 6.8). The supernatants were electrophoresed in a $10 \%$ SDS-polyacrylamide gel that was then fixed, treated with $\mathrm{En}^{3} \mathrm{Hance}$, and autoradiographed for $6 \mathrm{~d}$. Cold calf intestinal ADA and ${ }^{14} \mathrm{C}$-labeled proteins were used as molecular weight standards.

\section{Results}

ADA activities in cells from two members of the kindred and controls are shown in Table I. These data confirm the marked elevation in kindred erythrocyte ADA activity compared with that in normal and high-reticulocyte controls $(3,4)$. ADA activity in the proband-derived B lymphoblast line is comparable with
Table I. ADA Activity in Proband and Control Erythrocytes and Lymphoblast Cell Lines

\begin{tabular}{lc}
\hline Cell type & ADA activity \\
\hline & $n m o l / m i n / m g$ \\
Red blood cells & \\
Normal subjects & 1.1 \\
High-reticulocyte control & 1.0 \\
Proband & 74.9 \\
Affected relative & 105.3 \\
Cultured lymphoblasts & \\
GM-558 B lymphoblasts & 55.0 \\
Proband B lymphoblasts & 48.5 \\
MOLT-4 T lymphoblasts & 3,366 \\
\hline
\end{tabular}

that in the normal B lymphoblast cell lines and far less than that in a $\mathrm{T}$ lymphoblast cell line.

The amount of ADA immunoreactive protein in proband and control erythrocytes was estimated by Western blot analysis, as shown in Fig. 1. There is a markedly increased amount of immunoreactive ADA protein in the proband $\mathrm{RBC}$ lysate (lanes 1-3) at dilutions extending to $1: 80$ those of control RBC lysates (lanes 4 and 5). These data document that the elevation in erythrocyte ADA activity is associated with a corresponding increase in the amount of ADA protein. Western blot analysis of lysate from the proband B lymphoblast cell line demonstrated an ADA band equivalent in intensity to control B lymphoblast cell lines (data not shown).

Southern blots were performed to determine if the proband ADA gene was amplified or if there were major insertions, deletions, or rearrangements within the gene. A representative blot is shown in Fig. 2. The patterns of restriction fragments and the intensity of bands in the proband are identical to controls. No abnormal bands have been detected on Southern blots in which genomic DNA was digested with randomly chosen restriction endonucleases and enzymes site-specific for DNA corresponding to the 5' noncoding region of ADA mRNA (Alu I, Bal I, BamH I, EcoR I, Mbo I, Msp I, Nci I, Nco I, Pst I, Rsa I, Taq I). In view of these data, it is highly unlikely that gene amplification or major structural alterations in the proband ADA gene account for the increased amounts of ADA enzyme.

Northern blot analysis was used to assess the amount of ADA-specific mRNA in proband reticulocytes (Fig. 3). The amount of proband ADA mRNA (lane 1) is equivalent to that in RNA obtained from controls with hemolytic anemias (lanes $2-4)$, suggesting that the defect is not due to increased transcrip-

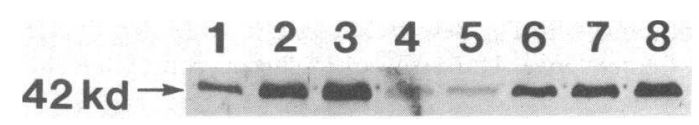

Figure 1. Western blot analysis of cell lysates. Lysates were electrophoresed on an SDS-10\% polyacrylamide gel, transferred to nitrocellulose, incubated with rabbit anti-ADA antibody and goat anti-rabbit serum conjugated to horseradish peroxidase, and stained for peroxidase activity. The bands shown comigrated with purified calf intestinal ADA with an apparent molecular weight of 42,000. Lanes $1-3,25 \mu \mathrm{g}, 50$ $\mu \mathrm{g}$, and $100 \mu \mathrm{g}$ of proband erythrocyte protein; lanes 4 and $5,2 \mathrm{mg}$ of erythrocyte protein from high reticulocyte controls; lanes 6-9, $0.5 \mu \mathrm{g}$, $1.0 \mu \mathrm{g}$, and $2.0 \mu \mathrm{g}$ of MOLT-4 T lymphoblast protein. 


\section{$\begin{array}{llllllllll}1 & 3 & 4 & 5 & 6 & 7 & 8 & 9 & 1011 & 12\end{array}$}

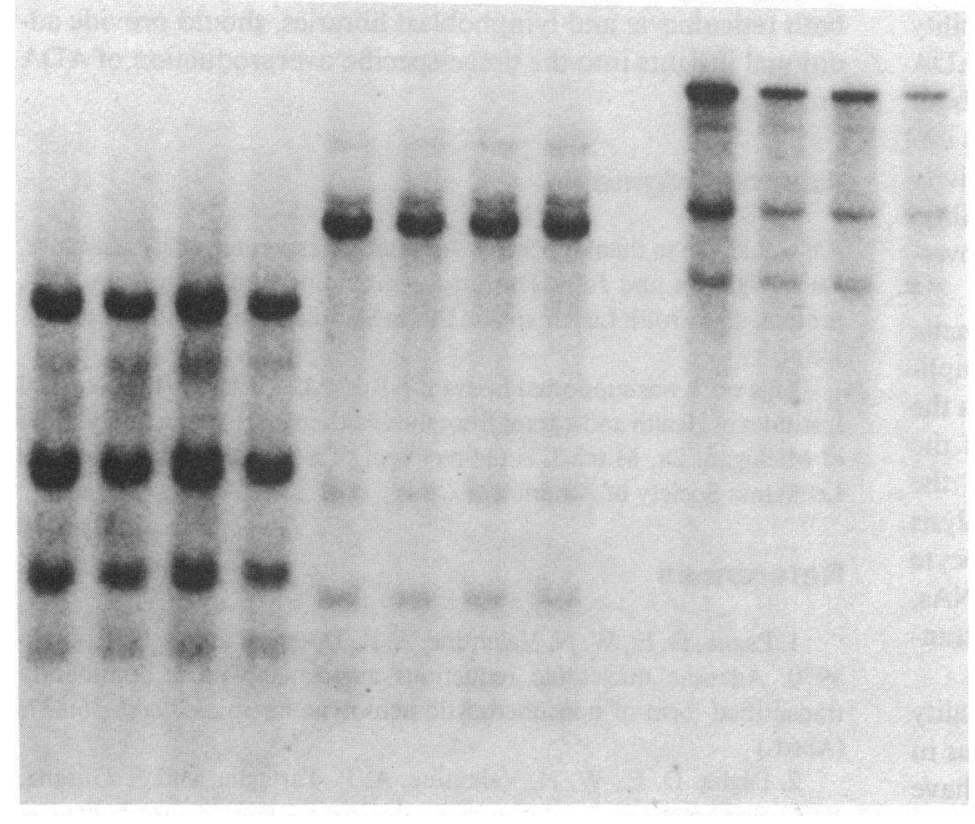

Figure 2. Southern blot analysis of genomic ADA from proband and controls. Lanes 1-4 were digested with Msp I, lanes 5-8 with Rsa I, and lanes 9-12 with Eco RI. Lanes 1, 5, and 9 contain proband DNA; lanes $2-4,6-8$, and $10-12$ contain DNA from three normal controls.

tion of the ADA gene or increased stability of the ADA mRNA in the reticulocyte. Northern blots were repeated with poly $\mathrm{A}^{+}$ RNA with similar results (data not shown). Representative blots were reprobed with an alpha-globin cDNA probe (20) to ensure that equal amounts of RNA were loaded and that the RNA was of reticulocyte origin (data not shown). Levels of ADA mRNA were also assessed in proband B lymphoblasts, control B lymphoblasts, and a $\mathrm{T}$ lymphoblast line with high ADA activity (Fig. 3). The amount of ADA mRNA in proband B lymphoblasts (lane 5) is similar to that in normal B lymphoblast controls (lanes

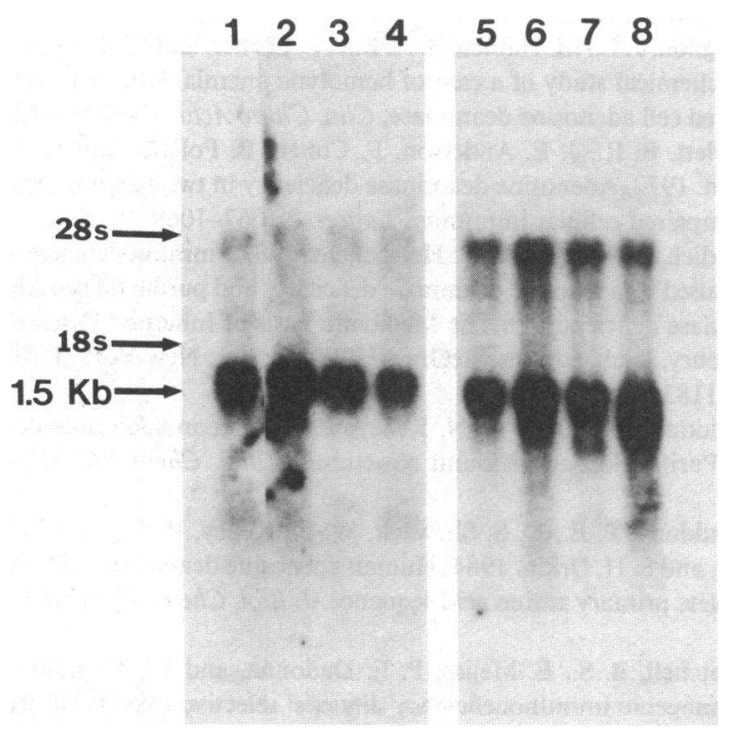

Figure 3. Northern blot analysis of ADA mRNA. Lane 1, proband reticulocyte RNA; lanes 2-4, reticulocyte RNA from three controls with hemolytic anemias; lane 5, proband B lymphoblast RNA; lanes 6 and 7, GM-558 and MGL-8 B lymphoblast RNA; lane 8, MOLT-4 T lymphoblast RNA. The $1.5-\mathrm{kb}$ band corresponding to ADA mRNA is indicated.
6 and 7) and significantly less than that in the T lymphoblast line (lane 8).

We then asked whether the increased amount of ADA protein in proband erythrocytes resulted from increased translation of the ADA mRNA. Poly $\mathrm{A}^{+}$mRNAs from the proband and a high-reticulocyte control were translated in vitro with incorporation of ${ }^{35} \mathrm{~S}$-methionine, immunoprecipitated with anti-ADA antibody, and electrophoresed as described in Methods. Results are shown in Fig. 4. Translation of proband mRNA produces a band of $\sim 42,000 \mathrm{~mol}$ wt (arrow, lane 4 ) that is significantly and specifically reduced in intensity in the presence of $11 \mu \mathrm{g}$ unlabeled human ADA protein (lane 5). This band is not present in proband samples incubated with preimmune serum (lane 3 ) or in control preimmune or immune precipitations (lanes 1 and 2). A similar band specific for the translation products of proband mRNA has been observed in three separate experiments.

\section{Discussion}

We have demonstrated that the elevated erythrocyte ADA activity in this kindred is associated with a corresponding increase in the amount of ADA immunoreactive protein. This finding is

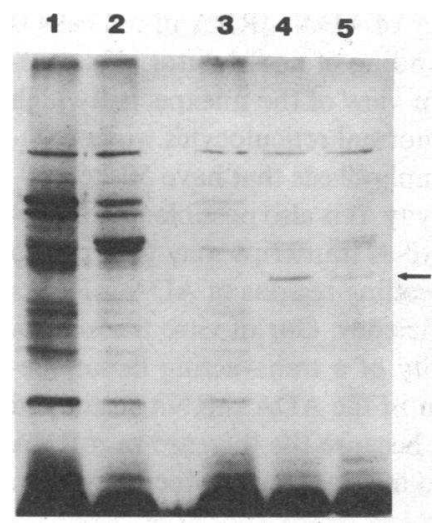

Figure 4. In vitro translation of reticulocyte mRNA and immunoprecipitation of protein products. Lanes 1 (control) and 3 (proband), translation products precipitated with preimmune rabbit serum. Lanes 2 (control) and 4 (proband), protein products precipitated with specific anti-ADA antibody. Lane 5 (proband), purified human ADA (11 $\mu \mathrm{g})$ added before precipitation with anti-ADA antibody. 
consistent with the data of Fujii et al. in cultured erythroid cells from a similar kindred (21). Such an increase could result either from overproduction of the enzyme or from increased stability of the protein in erythrocytes. Hirschhorn has shown that ADA activity in normal RBCs is highly stable with a half-life of about $231 \mathrm{~d}$ (22). Since the average RBC life span is $120 \mathrm{~d}$, it is impossible to attribute a 70 - to 100 -fold increase in ADA activity to a structural gene mutation that increases the protein stability. We therefore conclude that this disorder is due to ADA overproduction.

We have further investigated this defect at a molecular genetic level. By Southern blot analysis we have excluded gene amplification and large insertions, deletions, or rearrangements in the gene. If the defect were due to increased transcription of the gene or increased stability of erythrocyte ADA mRNA, the amount of ADA mRNA detectable by Northern blot analysis should be markedly increased. However, proband reticulocyte ADA mRNA was equal in size and amount to control mRNAs, suggesting that the defect is not mediated at the level of transcription or mRNA stability.

Our investigations suggest that the functional abnormality in ADA expression occurs at a posttranscriptional level. Our in vitro translation and immunoprecipitation experiments have consistently demonstrated a band of $\sim 42,000$ apparent mol wt that is synthesized from proband reticulocyte mRNA but not control mRNAs. These data strongly suggest that erythrocyte ADA overabundance in this disorder is due to an abnormality intrinsic to reticulocyte ADA mRNA that results in its increased translation.

There have been several examples of mutations reported to affect the translational efficiency of specific mRNAs. The degree of secondary structure of the $5^{\prime}$ noncoding region of the mRNA appears to be inversely proportional to the translational efficiency of the mRNA (23). For example, rearrangement of the c-myc protooncogene resulting in truncation of the $5^{\prime}$ region and the inability to form a stable stem-loop structure has been reported to increase the translation of $c-m y c$ mRNA (24). This observation is of particular interest because the $5^{\prime}$ noncoding region of ADA mRNA is comprised of $80 \%$ guanosine and cytosine residues $(10,25,26)$ with considerable potential for formation of stable secondary structures. Mutations in this region and consequent loss of secondary structure might result in increased ribosomal binding to and/or scanning of the mRNA. Point mutations flanking the initiation codon have also been shown to alter translational efficiency (27).

The mechanism underlying the tissue specificity of this defect is not yet clear. Inhibitors of translation have been demonstrated in erythroid cells (28), and one potential mechanism for specific increased translational efficiency of ADA mRNA in red cells is a mutation that prevents the binding of an inhibitor. This possibility is especially intriguing in view of the unexpectedly high abundance of ADA mRNA in normal reticulocytes when compared with the amount in B lymphoblasts that have 50- to 100fold higher ADA enzymatic activity. It is also possible that tissuespecific splicing of a primary RNA transcript may give rise to minor differences in the $5^{\prime}$ noncoding regions of ADA mRNAs that thus affect translational efficiency. Our in vitro translation experiments make the possibility of a trans-acting factor specifically affecting the translation of the ADA mRNA in the red cells of this kindred less likely, because the increase in mRNA translation can be demonstrated in a rabbit reticulocyte system.
Further elucidation of the specific defect in this disorder, including the cloning and sequencing of ADA cDNA clones from both reticulocyte and lymphoblast libraries, should provide additional insights into the tissue-specific overproduction of ADA protein.

\section{Acknowledgments}

We would like to thank Elizabeth Ashcraft for expert technical assistance, Dan Wiginton and John Hutton for providing purified human ADA protein, and Ardith Listeman and Susan Siaczka for help with the manuscript.

This work was supported by grant 1-R01-AI24012 from the National Institutes of Health and a grant from the Children's Leukemia Foundation of Michigan. Dr. Mitchell is the recipient of a Scholar Award from the Leukemia Society of America.

\section{References}

1. Paglia, D. E., W. N. Valentine, A. P. Tartaglia, and P. N. Konrad. 1970. Adenine nucleotide reductions associated with a dominantly transmitted form of nonspherocytic hemolytic anemia. Blood. 36:837. (Abstr.)

2. Paglia, D. E., W. N. Valentine, A. P. Tartaglia, and F. Gilsanz. 1976. Perturbations in erythrocyte adenine nucleotide metabolism: a dominantly inherited hemolytic disorder with implications regarding normal mechanisms of adenine nucleotide preservation. Blood. 48:959. (Abstr.)

3. Valentine, W. N., D. E. Paglia, A. P. Tartaglia, and F. Gilsanz. 1977. Hereditary hemolytic anemia with increased red cell adenosine deaminase (45- to 70-fold) and decreased adenosine triphosphate. Science (Wash. DC). 195:783-785.

4. Paglia, D. E., W. N. Valentine, A. P. Tartaglia, F. Gilsanz, and R. S. Sparkes. 1978. Control of red blood cell adenine nucleotide metabolism: studies of ADA. In The Red Cell. G. Brewer, editor. Alan R. Liss, Inc., New York. 319-335.

5. Miwa, S., H. Fujii, N. Matsumoto, N. Tadako, S. Oda, H. Asano, and S. Asano. 1978. A case of red-cell adenosine deaminase overproduction associated with hereditary hemolytic anemia found in Japan. Am. J. Hematol. 5:107-115.

6. Perignon, J. L., M. Hamet, H. A. Buc, P. Cartier, and M. Derycke. 1982. Biochemical study of a case of hemolytic anemia with increased (85-fold) red cell adenosine deaminase. Clin. Chim. Acta. 124:205-212.

7. Giblett, E. R., J. E. Anderson, F. Cohen, B. Pollara, and H. J. Meuwissen. 1972. Adenosine deaminase deficiency in two patients with severely impaired cellular immunity. Lancet. 2:1067-1069.

8. Kredich, N. M., and M. S. Herschfield. 1983. Immunodeficiency diseases caused by adenosine deaminase deficiency and purine nucleoside phosphorylase deficiency. In The Metabolic Basis of Inherited Disease. J. B. Stanbury, et al., editors. McGraw-Hill Book Co., New York. Fifth ed. 1157-1183.

9. Daddona, P. E., and W. N. Kelley. 1977. Human adenosine deaminase: Purification and subunit structure. J. Biol. Chem. 252:110115.

10. Daddona, P. E., D. S. Shewach, W. N. Kelley, P. Argos, A. F Markham, and S. H. Orkin. 1984. Human adenosine deaminase: cDNA and complete primary amino acid sequence. J. Biol. Chem. 259:1210112106.

11. Mitchell, B. S., E. Mejias, P. E. Dadonna, and W. N. Kelley. 1978. Purinogenic immunodeficiency diseases: selective toxicity of deoxyribonucleosides for T cells. Proc. Natl. Acad. Sci. USA. 75:50115014.

12. Laemmli, U. K. 1970. Cleavage of structural proteins during the assembly of the head of bacteriophage T4. Nature (Lond.). 227:680-685.

13. Towbin, H., T. Staehelin, and J. Gordon. 1979. Electrophoretic transfer of proteins from polyacrylamide gels to nitrocellulose sheets: 
procedures and some applications. Proc. Natl. Acad. Sci. USA. 76:43504354.

14. Mitchell, B., Edwards, N. L., and Koller, C. 1983. Deoxyribonucleoside triphosphate accumulation by leukemic cells. Blood. 62:419424.

15. Bell, G. I., J. H. Karam, and W. J. Rutter. 1981. Polymorphic DNA regions adjacent to the $5^{\prime}$ end of the human insulin gene. Proc. Natl. Acad. Sci. USA. 78:5759-5763.

16. Maniatis, T., E. F. Fritsch, and J. Sambrook. 1982. Molecular Cloning. Cold Spring Harbor, New York.

17. Aviv, H., and P. Leder. 1972. Purification of biologically active globin messenger RNA by chromatography and oligothymidylic acidcellulose. Proc. Natl. Acad. Sci. USA. 69:1408-1412.

18. Wilson, J. M., B. W. Baugher, P. M. Mattes, P. E. Daddona, and W. N. Kelley. 1982. Human hypoxanthine-guanine phosphoribosyltransferase: demonstration of structural variants in lymphoblastoid cells derived from patients with a deficiency of the enzyme. J. Clin. Invest. 69:706-715.

19. Kessler, S. W. 1981. Use of Protein A-bearing Staphylococci for the immunoprecipitation and isolation of antigens from cells. Methods Enzymol. 73:442-459.

20. Wilson, J. T., L. B. Wilson, J. K. deRiel, L. Villa-Komaroff, A. Efstradtiadis, B. G. Forget, and S. M. Weissman. 1978. Insertion of synthetic copies of human globin genes into bacterial plasmids. Nucleic Acids Res. 5:563-581.

21. Fujii, H. S., S. Miwa, K. Tani, N. Fujinami, and H. Asano. 1982.
Overproduction of structurally normal enzyme in man; hereditary haemolytic anaemia with increased red cell adenosine deaminase activity. Br. J. Haematol. 51:427-430.

22. Hirschhorn, R., V. Roegner, T. Jenkins, C. Seaman, S. Piomelli, and W. Borkowsky. 1979. Erythrocyte adenosine deaminase deficiency without immunodeficiency. J. Clin. Invest. 56:1130-1139.

23. Pelletier, J., and N. Sonenberg. 1985. Insertion mutagenesis to increase secondary structure within the $5^{\prime}$ noncoding region of eukaryotic mRNA reduces translational efficiency. Cell. 40:515-526.

24. Darveau, A., J. Pelletier, and N. Sonenberg. 1985. Differential efficiencies of in vitro translation of mouse $c-m y c$ transcripts differing in the 5' untranslated region. Proc. Natl. Acad. Sci. USA. 82:2315-2319.

25. Wiginton, D. A., G. S. Adrian, and J. J. Hutton. 1984. Sequence of human adenosine deaminase cDNA including the coding region and a small intron. Nucleic Acids Res. 5:2439-2446.

26. Valerio, D., M. G. C. Duyvesteyn, B. M. Dekker, G. Weeda, T. M. Berkvens, L. van der Voorn, H. van Ormondt, and A. J. van der Erb. 1985. Adenosine deaminase: characterization and expression of a gene with a remarkable promoter. $E M B O$ (Eur. Mol. Biol. Organ.) J. 4: 437-443.

27. Kozak, M. 1984. Point mutations close to the AUG initiation codon affect the efficiency of translation of preproinsulin in vivo. Nature (Lond.). 308:243-246.

28. Knoller, S., and R. Kaempfer. 1984. Initiation of heme-controlled inhibitor of translation that blocks the interaction between messenger RNA and the eukaryotic initiation factor 2. Biochemistry. 23:2462-2469. 